$\begin{array}{ll} & \text { Etnográfica } \\ \text { etnográfica } & \text { Revista do Centro em Rede de Investigação em }\end{array}$

Antropologia

vol. 25 (3) | 2021

Vol. 25 (3)

\title{
Entre bonecas e parentes: uma reflexão sobre as ritxo(k)o karajá
}

Between dolls and parents: a reflection on ritxo(k)o karajá

Joana Silva de Araujo Farias

\section{(2) OpenEdition}

Journals

Edição electrónica

URL: https://journals.openedition.org/etnografica/10249

DOI: 10.4000/etnografica.10249

ISSN: 2182-2891

\section{Editora}

Centro em Rede de Investigação em Antropologia

Edição impressa

Data de publição: 1 outubro 2021

Paginação: 771-794

ISSN: 0873-6561

Refêrencia eletrónica

Joana Silva de Araujo Farias, «Entre bonecas e parentes: uma reflexão sobre as ritxo(k)o karajá », Etnográfica [Online], vol. 25 (3) | 2021, posto online no dia 28 outubro 2021, consultado o 10 janeiro 2022. URL: http://journals.openedition.org/etnografica/10249 ; DOI: https://doi.org/10.4000/ etnografica. 10249

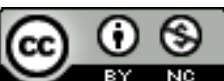

Etnográfica is licensed under a Creative Commons Attribution-NonCommercial 4.0 International License. 


\section{Entre bonecas e parentes: uma reflexão sobre as ritxo(k)o karajá}

\section{Joana Silva de Araujo Farias}

O presente artigo busca revisitar o tema das bonecas karajá a partir de extensa revisão da bibliografia e de minha experiência em campo. A intenção é articular duas discussões historicamente separadas nas pesquisas sobre os Karajá: os estudos sobre os objetos e as discussões sobre a produção da pessoa, parentesco e corpo. Defendo que as ritxo(k)o fazem parte das redes de relações de parentesco. A produção, a venda ou o presentear das peças ativa relações entre grupos de mulheres. Ao mesmo tempo, o ato de presentear as meninas pequenas com ritxo(k)o integra um conjunto de atos que constroem corpos aparentados, como os de avó e neta. As ritxo(k)o também são um modo de estabelecer relações com a alteridade dos brancos através do presente, da venda e da relação com pesquisadores. Com os benefícios adquiridos das relações com os brancos, os Karajá põem em movimento, novamente, a produção dos corpos aparentados, transformando dinheiro e bens materiais em comida e presentes para sua família. A alimentação, os cuidados diários, o uso dos termos corretos de parentesco e presentes, como as ritxo $(k)$, mas também de bens industrializados, a troca de afetos, o aconselhamento, a proteção através da categoria de brotyré são parte das ações que garantem um processo bem-sucedido de parentesco.

PALAVRAS-CHAVE: karajá, bonecas karajá, pessoa, parentesco, corpo

Between dolls and parents: a reflection on ritxo(k)o karajá - This article aims to revisit the theme of the karajá dolls reflecting upon a broad bibliography review and my field work. The goal is to articulate two historically separated discussions in Karajá's research: the study on objects and the discussions about the personhood, kinship and body. I argue that the ritxo(k)o are part of the networks of kinship relationships. Their production, sale or gifting activates relationships between groups of women. At the same time, the act of gifting ritxo(k)o to small girls is part of a set of acts that builds kin-bodies, such as grandmother and granddaughter. The ritxo(k)o are also a way of establishing relationships with the alterity of white people, either through gifting, selling or by establishing a relationship with researchers. Using the benefits gained from these relationships, the Karajá set in motion, once again, the production of kin-bodies, turning money and material goods into food and gifts for their family. Food, daily care, use of the correct terms of kinship and gifts, such as ritxo(k)o, but also industrialized goods, the exchange of affections, advice, protection through the brotyré category are part of the actions that guarantee a successful kinship process.

KEYWORDS: karajá, karajá doll, personhood, kinship, body

FARIAS, Joana Silva de Araujo (joana.farias@usp.br) - Departamento de Antropologia, Universidade de São Paulo, Brasil 


\section{INTRODUÇÃO}

Os grupos karajá ocupam, atualmente, território que segue o curso do rio Araguaia. A língua Karajá pertence ao tronco Macro-Jê, e é composta por três dialetos distintos: o Karajá, o Javaé e o Xambioá (Davies 1968). Esses dialetos marcam também diferentes grupos. ${ }^{1}$ Tanto os Karajá como os Javaé se autodenominam Injy. A atividade oleira é muito difundida entre as mulheres karajá, e sua venda é fonte importante de renda para muitas famílias. Conhecidas como bonecas karajá, as ritxo(k)o são as peças de cerâmica que são muito apreciadas pelos tori (os brancos) no mercado de arte étnica (Whan 2010). ${ }^{2}$ Elas também são mencionadas em pesquisas desde o final do século XIX, sendo registrado seu uso pelas meninas karajá como brinquedo. A arqueóloga Irmhild Wüst (1975), por exemplo, notou a presença das ritxo(k)o entre as crianças karajá. Segundo ela, as meninas brincavam com essas peças e tinham mais ou menos trinta delas, "todas vestidas". "Em geral, as colocavam em posição de dormir, tanto em rede como na cama." (Wüst 1975: 134).

Além disso, as ritxo(k)o foram coletas para a formação de coleções, que atualmente podem ser encontradas por todo Brasil e pelo mundo, e também foram foco de estudos antropológicos, sendo um dos temas mais explorados na bibliografia sobre os Karajá (Campos 2007; Faria 1959; Whan 2010; Chiara 1970; Costa 1968; Lima e Silva 2011; Simões 1992). Em 2012, o "Ofício e os Modos de Fazer as Bonecas Karajá" foi registrado como Patrimônio Cultural Imaterial do Brasil pelo IPHAN (Instituto do Patrimônio Histórico e Artístico Nacional). As ritxo(k)o foram inscritas no Livro dos Saberes e, ainda, no Livro das Formas de Expressão, como patrimônio cultural brasileiro.

Esse artigo é fruto da pesquisa que realizei no mestrado. ${ }^{3}$ Ela baseou-se fortemente na revisão crítica da bibliografia, mas também contou com pesquisa de campo na aldeia de Santa Isabel do Morro (TO) por duas semanas. ${ }^{4}$

I É importante ressaltar que, segundo Rodrigues (2008), os Javaé possuem importante projeto político em que procuram se destacar e se distanciar dos Karajá, projetando no cenário nacional sua própria identidade étnica.

2 A língua karajá apresenta "variação diastrática de gênero: a fala dos homens, habu rybe, e a fala das mulheres hawoky rybe." (Whan 2010: viii). Essa diferenciação geralmente ocorre pela inserção de consoantes (em sua maioria o "k") na fala feminina em encontros vocálicos da fala masculina, mas também em algumas palavras que iniciam por vogal. Adoto aqui a representação gráfica criada por Eduardo Nunes (2012) que permite que ambas as falas sejam representadas, através da inserção da consoante da fala feminina entre parêntesis, como em ta(k)ina. Essa é uma solução elegante para contemplar as duas falas karajá. 3 O intuito de minha pesquisa de mestrado (Farias 2015) era refletir sobre a pertinência de pensar a ritxo(k)o enquanto boneca e de entender esse tema clássico da bibliografia a partir da valorização da experiência da criança. Ela contou com financiamento da FAPESP e CNPq.

4 A pesquisa de campo ocorreu em julho de 2012. Ela foi possível graças ao financiamento da pesquisa temática "Redes Ameríndias: geração e transformação nas terras baixas Sul-americanas" (CestA-USP). Muitas das reflexões aqui apresentadas também são fruto das discussões e reflexões feitas no âmbito desse grupo. 
Apesar do curto período de tempo passado em campo, as experiências vividas em Santa Isabel mudaram minha leitura da bibliografia. Foi sentada no pátio da casa de Komytira, minha anfitriã, e rodeada por suas filhas, netas e netos que percebi como as relações da ritxo $(k) o$ estavam ligadas a um processo mais amplo de produção de parentesco. Meu intuito em revisitar o tema das ritxo(k)o é a possibilidade de criar relações entre a extensa pesquisa voltada para cultura material e as reflexões sobre produção da pessoa, parentesco e corpo, que se tornaram centrais para a etnologia sul-ameríndia. Apoiada em propostas recentes sobre o lugar dos objetos nas redes de relações (Gell 1998; Santos-Granero 2013), pretendo mostrar que essa cerâmica se inscreve num processo de produção de corpos aparentados. O extenso material produzido sobre as ritxo(k)o e as discussões recentes da etnologia sul-ameríndia sobre o parentesco e a produção da pessoa, mesmo que contemplados na bibliografia karajá, encontram-se pouco articulados. Segundo Viveiros de Castro (1999), os anos 1970 marcaram um amplo e concertado passo adiante para a etnologia sul-ameríndia, graças a produção etnográfica acumulada no período, que garantiu importantíssimos avanços teóricos. Se esse novo passo significou um aumento significativo das pesquisas realizadas entre os Karajá (Toral 1992; Lima Filho 1991, 1994; Donahue 1982; Pétesch 1992), ele também resultou num desinteresse pelas ritxo(k)o. As teses de Campos (2007) e Whan (2010) retomam o interesse pelo tema, mas têm pouco diálogo com os avanços teóricos produzidos pela etnologia sul-ameríndia contemporânea.

Na primeira seção, apresento brevemente o fazer cerâmico entre os Karajá, mostrando como essa prática está permeada pelas relações entre parentes. No pátio de suas casas, junto de suas irmãs, filhas e filhos, as mulheres moldam o barro, criando suas figuras cerâmicas. A obtenção dos materiais, a produção das peças e a venda é uma atividade que envolve todo o grupo familiar. Fazer e vender cerâmica não é um ato solitário, mas um processo que envolve ceramistas, maridos, filhos e filhas, e irmãs.

A parte seguinte volta-se para o lugar dos objetos nas teorias antropológicas. Desde a década de 1960, o estudo da cultura material busca se afastar da herança do colecionismo. Recentemente, a etnologia vem propondo um lugar ainda mais central para os objetos: são parte da rede de relações das pessoas (Gell 1998). Ademais, salientarei a importância de superar a dicotomia entre ritual e cotidiano, permitindo pensar sobre os objetos de forma mais plástica. Entre os ameríndios, os objetos são permeados pelas relações em suas vizinhanças (Santos-Granero 2013).

Logo após essa reflexão, a questão do parentesco é explorada com atenção, a partir das teorias contemporâneas sobre parentesco sul-ameríndio, enfatizando que este é um processo que se desvela no próprio corpo. Ao nascer, o bebê karajá ainda não é considerado parente, podendo ser identificado à categoria de alteridade aõni (Nunes 2012). Os cuidados com o corpo que seguem são 
muitos: ornar, alimentar, estar sempre perto de um corpo-parente. A criança vai se fazendo parente nessas relações que se estabelecem. Outro elemento essencial na produção dos corpos-parentes é abordado na seção seguinte: a memória. Lembrar e ser lembrado pelos parentes é um importante sinal de que o processo de aparentamento foi bem-sucedido (Nunes 2012). Uma categoria importante na evocação dessa memória do parentesco é a dos brotyrè. ${ }^{5}$ Mas, se o ato de lembrar dos carinhos e cuidados efetiva esse processo, a memória de agressões e desavenças também pode enfraquecer e romper o aparentamento.

A partir do entendimento de que o parentesco deve ser constantemente produzido e que ele pode falhar ou ser desfeito, as diversas ações e cuidados para produzir-se enquanto corpos-parentes assumem a devida importância. Entre os ameríndios, o parentesco é um processo permeado pelo perigo de não se conseguir efetivá-lo. É a partir dessa perspectiva que proponho, na seção que segue, revisitar um aspecto registrado na bibliografia como o uso "original" ou "antigo" das ritxo $(k) o$ : as avós que presenteiam as netas com um conjunto de bonecas (Costa 1968; Simões 1992; Campos 2007; Whan 2010). A partir de uma situação vivida durante a pesquisa de campo, proponho que o ato de presentear as meninas com ritxo( $k$ )o é uma das ações que podem produzir corpos aparentados. Não é por que se é avó que se busca presentear as netas, mas é através do ato de presentear que a mulher se faz avó e faz, ao mesmo tempo, a neta.

As duas últimas seções voltam-se para as relações estabelecidas com os brancos, os tori. Primeiramente, mostrando que tipos de relações os Karajá estabelecem com eles via ritxo(k)o. O contato dos Karajá com os brancos é bastante antigo, mas é na época de Getúlio Vargas e Juscelino Kubitschek, que tinham a ocupação do centro-oeste em seu centro, que essas relações assumem um âmbito nacional (Pétesch 1992). As relações amistosas entre o governo e os Karajá tiveram grande visibilidade, assumindo a ritxo(k)o o papel de emblema da cultura. Além disso, tornaram-se artigo popular entre os turistas que visitavam a região do Araguaia (Chiara 1970). Os estudos da época atribuem a essa efervescência política e econômica uma mudança na forma de fazer ritxo(k)o que buscava impulsionar as vendas e agradar o público tori (Simões 1992; Faria 1959; Costa 1968; Chiara 1970). Whan (2010) ressalta que as relações com os brancos podem ser de amizade ou comerciais. Defendo ainda um terceiro tipo de relação, que se estabelece com pesquisadores. Também mediada pelas ritxo(k)o, o que se estabelece não é apenas a obtenção de dinheiro, mas outros tipos de parceria, como a que culminou com o processo de patrimonialização.

5 Brotyrè é uma posição assumida pelos parentes em situações de limiaridade. Nesses momentos, os brotyrè agem como protetores das crianças, algumas vezes usando do próprio corpo para fazer essa proteção (Lima Filho 1991; Toral 1992). 
Na seção que segue, apresento o argumento de que mesmo as relações com os brancos podem ser instrumento do processo de produção de corpos-parentes. Para isso, primeiro apresento como a alteridade tem lugar na produção de parentesco karajá a partir da transmissão de ijasò ${ }^{6}$ Defendo que, assim como transmitir o ijasò para uma criança é uma forma adequada de entrar em contato com essa alteridade e dela obter benefícios que permitem aparentá-la de forma boa e correta, também é o comércio de ritxo(k)o. Esta é uma das formas adequadas de entrar em contato com a alteridade dos tori e deles conseguir benefícios, como o dinheiro. Este é, então, usado para a compra de comida e presentes que são essenciais para a produção dos corpos-parentes. Dessa forma, a venda de ritxo(k)o pode mobilizar relações com os próprios tori ou também ser parte do processo de produção de corpos-parentes.

\section{A CERÂMICA ENTRE OS KARAJÁ}

A atividade oleira entre os Karajá é feminina. As mulheres são responsáveis por iniciar essa atividade, mesmo que precisem de auxílio de seus maridos ou filhos. A coleta do barro é feita normalmente na época da seca, quando o nível do rio Araguaia abaixa drasticamente e fica fácil acessar os lugares de extração. Estes são locais bem conhecidos pelas ceramistas, nos quais se encontra barro vermelho e branco. O primeiro tipo é o ideal para potes e panelas, enquanto o segundo é recolhido para fazer as ritxo( $k$ )o.

A retirada do barro é trabalho muito pesado, por isso, pode ser necessário chamar maridos ou filhos, para carregar o barro em carrinhos de mão. Não é incomum que as ceramistas estoquem o barro seco em suas casas. Para obter essa massa com que modelam suas figuras cerâmicas, é preciso misturar água, barro e a cinza de uma árvore chamada hadena, uma madeira muito dura. Essa cinza é essencial para fazer cerâmica, é com a proporção certa entre cinza e barro que a cerâmica fica resistente o bastante para não rachar (Whan 2010: 124). Whan (2010) observa que cada mulher, ou cada grupo de parentas, tem sua própria receita para a produção dessa massa. As cinzas devem ser mantidas longe das crianças da casa, pois em contato com a pele causam coceira.

As ceramistas se dedicam a modelagem durante a tarde ou depois do jantar. Com a massa que já se tem guardada em mãos, senta-se na esteira, junto da

6 Em suas histórias de origem, os Karajá, ou iñ̃ como se autodenominam, saíram do fundo do rio Araguaia (Pétesch 1992). Alguns inỹ ficaram para trás, e mantêm o mesmo modo de vida do fundo das águas, onde há imortalidade e impossibilidade de mudanças (Pétesch 1992; Toral 1992). É essa condição estática que permite aos inỹ aquáticos conservar um saber sociocultural especificamente inỹ, que eles reintroduzem regularmente entre os Karajá através dos rituais, assumindo a posição de ijasò. Outra posição que pode ser assumida por diversas entidades do cosmo é a de aõni. Estas são entidades carnívoras, canibais e predadoras dos humanos. Os aõni não vivem em grupos organizados, vivem em selvageria e sozinhos (Pétesch 1992). 
família, e a argila vai tomando forma em meio a conversas animadas. As meninas pequenas ficam muito interessadas na modelagem, pedindo pedaços de argila para brincar. Para modelar, é preciso um pote com água, para umedecer constantemente a massa, além de uma tábua de madeira para apoiar as peças já modeladas. Depois da peça pronta, a ceramista se preocupa em deixá-las num local seco e afastado das crianças para secagem. Enquanto a argila sem forma é rapidamente oferecida às meninas pequenas, as peças já modeladas são afastadas delas invocando a possibilidade de quebra.

Antes de serem queimadas as peças podem passar por um processo de raspagem, em que se tira o excesso de massa e se define os contornos com mais detalhe (Whan 2010). Os locais escolhidos para a queima normalmente são um pouco afastados da casa, mas não tão distantes que as ceramistas não possam participar das atividades que estão ocorrendo no pátio de suas casas. Isso é uma diferença importante que me foi ressaltada com relação à queima de ritxo(k)o e a queima de outras cerâmicas, como panelas e potes. As primeiras podem ser queimadas no pátio da casa, enquanto para as panelas e potes era preciso procurar um lugar afastado e silencioso, porque mesmo o barulho podia rachá-las. A queima ocorre em duas etapas. Na primeira, pode-se usar qualquer tipo de madeira, e ao final as peças assumem uma cor escura. Para a segunda, é preciso buscar certos tipos de madeira, podendo ser hulalako, mykako ou hadejeko. Depois da segunda queima, as peças tomam uma cor clara. A coleta dessas madeiras é feita em conjunto com homens da casa, indo-se buscar a madeira em locais já conhecidos pela ceramista e sua família.

O processo de pintura exige que se tenha produzido as tintas anteriormente. A tinta vermelha pode ser produzida a partir do urucu misturado ao óleo de babaçu. A tinta preta se faz da casca de galhos verdes de uma árvore chamada ixarurina, à qual também se mistura fuligem - do fundo das panelas ou da queima de pneus. A pintura é processo delicado e preciso, mas acaba sendo retardado pelos constantes cuidados que precisam os filhos e netos. Como para modelar, as ceramistas sentam-se sobre esteiras, e sua família se reúne ao seu redor. Passam-se as tardes conversando e pintando a cerâmica, os vizinhos chegam e juntam-se à conversa. Pinta-se primeiro com a tinta preta, e só depois de terminadas todas as peças, passa-se ao vermelho.

A maioria das peças produzidas pelas ceramistas é destinada ao comércio. Algumas vezes as ceramistas recebem encomendas, mas normalmente vendem suas peças na cidade de São Félix do Araguaia, que é frequentada quase diariamente, ou em viagens para cidades mais distantes como Goiânia, Brasília e Palmas. A venda não é uma atividade feita individualmente, ela aciona uma rede de mulheres da mesma família, que podem levar as peças das parentas para vender quando vão à cidade ou fazem uma viagem mais longa. Segundo Whan (2010), as ritxo(k)o são peças muito apreciadas no mercado de "arte étnica", mas também são muito vendidas para os turistas, principalmente 
durante a época de seca, em que as praias do Araguaia atraem muitos deles à região. O fazer cerâmico entre os Karajá mobiliza os parentes. Tanto na hora de produzir quanto de vender as peças.

\section{OS OBJETOS EM REDE}

Depois dos anos 1950, o estudo dos objetos indígenas afastou-se do colecionismo e das teorias que eram produzidas apenas nos museus. Novas abordagens surgiram para estudá-los e, apesar de profundas diferenças, todas ressaltam a importância da contextualização. Não mais deixar os "objetos fora da vida", como descrevia Berta Ribeiro (1986).

Dentre as muitas possibilidades que atualmente temos para abordar os objetos, a que inspirou minhas reflexões sobre as ritxo( $k$ )o foram os escritos de Alfred Gell (1998). As propostas do autor operam a aproximação de duas áreas que estavam tradicionalmente afastadas na antropologia britânica: a antropologia social e os estudos de cultura material (Strathern 1996). E é o mesmo tipo de aproximação que busco ao relacionar os estudos sobre as ritxo(k)o e temas mais contemporâneos da etnologia sul-ameríndia. A partir das propostas do autor, foi-me possível olhar para os objetos para além de seus usos e sua simbologia. Focar o olhar nas relações que as pessoas estabelecem com os objetos e através dos objetos.

Gell (1998) propõe duas rupturas significativas com as tradições anteriores. A primeira ruptura está ligada à questão da estética. Ele recusa a estética como uma categoria que possa ser estendida a qualquer cultura. Esse ponto já havia sido defendido por outros antropólogos, principalmente etnólogos que trabalhavam na região das terras baixas da América do Sul, como Joanna Overing (1996) e Peter Gow (1996). A base para a defesa desse argumento é que muitos dos objetos, que posteriormente são classificados como arte, não são produzidos com a intenção de provocar apreciação estética, mas são produzidos para serem eficazes. Muitas das propriedades estéticas dos objetos estão ligadas à sua funcionalidade e à sua eficácia dentro de contextos sociais específicos. Segundo Overing (1996), a produção dos objetos e sua decoração estão associados à sua potência. O mesmo também pode ser dito para as pessoas: objetos e pessoas são belos por aquilo que fazem no mundo social (Overing 1996). "In other words, the distinction we make between 'mere' decorations and function is unwarranted; decoration is intrinsically functional, or else its presence would be inexplicable." (Gell 1998: 74).

A segunda ruptura diz respeito ao simbolismo e à semiótica. Gell (1998) recusa, de forma categórica, as analogias entre arte e linguística. Ele argumenta que através da língua se pode falar sobre os objetos e atribuir-lhes significado, mas os objetos de arte não são parte da linguagem e nem constituem uma linguagem alternativa: "We talk about objects, using signs, but art objects are 
not, except in special cases, signs themselves, with 'meaning'" (Gell 1998: 6). Ao recuperar o trabalho do antropólogo Nicolas Thomas, o argumento da recusa da semiótica torna-se mais palpável. Thomas explora a questão da construção das Maori Meeting Houses a partir da década de 1870. Nesse período, os maori foram impedidos de competir entre si (e com os europeus) através das guerras tradicionais. Seu espírito competitivo voltou-se então para construção de Meeting Houses, cada vez maiores e com entalhes e pinturas mais elaborados, sempre com o intuito de sobrepujar seus vizinhos e rivais. "Houses were not 'symbols' but vehicles of a collectivity's power. They simultaneously indexed a group's own vitality and ideally or effectively disempowered others." (Nick Thomas, apud Gell 1998: 251). Mais do que símbolos, ou representações, essas grandiosas construções eram apresentações de eficácia coletiva.

Partindo dessa dupla ruptura, o autor volta a sua atenção para o papel prático de mediação exercido pelos objetos nos processos sociais. Ele busca mostrar que os objetos não são coisas inertes, mas sim um sistema de ação, um modo de agir sobre o mundo. Além disso, o autor ressalta que eles estão amplamente envolvidos em relações sociais. Avançando nas propostas de Mauss, que sugeriu que as dádivas são extensões das pessoas, Gell propõe que consideremos os objetos como se fossem pessoas. Mesmo que os objetos não o sejam propriamente, eles podem assumir o papel de pessoa contextualmente. $\mathrm{Ou}$ seja, é inseridos em relações sociais que os objetos podem assumir posição de agentes (Gell 1998: 7). Nesse sentido, as propostas do antropólogo britânico se confundem com as teorias nativas sobre o corpo e a pessoa, o que faz muito sentido no contexto sul-ameríndio, onde a agência pode ser revindicada por diversos habitantes do cosmo.

A maioria dos objetos analisados na obra de Gell (1998) são integrantes de rituais, o que deixa em aberto a questão dos objetos que pertencem à vida cotidiana. Muitos dos objetos que assumem a posição de pessoa são objetos excepcionais, que aparecem em contextos muito específicos, como é o caso das máscaras de apapaatai no Alto Xingu (Neto 2008) e das máscaras de ijasò entre os Karajá (Lima Filho 1991; Pétesch 1992; Toral 1992). As propostas do antropólogo britânico sobre os objetos não recusam a importância de pensá-los no cotidiano. $\mathrm{O}$ autor sugere que os objetos só aparecem como agentes em contextos sociais específicos. Por outro lado, ele enfatiza que os objetos estão inseridos nas redes de relações das pessoas: eles coabitam seu cotidiano.

Mas é possível ir além e recusar a dicotomia entre ritual e cotidiano. Se existem objetos com que se pode entrar em contato diariamente, sem muitos perigos, há objetos que apresentam verdadeiro perigo, e com os quais só se pode relacionar tomando muitas precauções. Voltemos ao contexto karajá. As ritxo(k)o, por exemplo, são objetos que podem ser produzidos e usados no pátio da casa e próximo a diversas categorias de pessoas. Mas nem todos os objetos são assim. Com as máscaras de ijasò é preciso ter muitos cuidados. Elas devem 
ser produzidas na mata, longe dos olhos da maioria das pessoas, que devem ser alimentadas e mantidas na sua própria casa (ijasò heto - casa dos ijasò), e só podem sair e serem vistas por todos em situações muito particulares, que nós chamamos de rituais. Entre esses dois extremos existem muitos objetos intermediários, como as panelas. Se, por um lado, podem conviver cotidianamente com todas as pessoas, por outro, não podem ser produzidas em áreas do convívio doméstico.

A coletânea organizada por Fernando Santos-Granero (2013) também reflete sobre a importância dos objetos na vida das pessoas. Focada no contexto amazônico, a coletânea também explora as aproximações entre a materialidade e a pessoa. E também prescinde da dicotomia ritual e cotidiano. Segundo Santos-Granero, a pessoa ameríndia é volátil e relacional, ela é composta dos relacionamentos que estabelece com o mundo. Do mesmo modo é objeto entre os ameríndios. Ele é permeado pelas relações do seu entorno, e, em consequência, pode ser inconstante. Dessa forma, um objeto que não assume papel de agente, também pode ser embutido de subjetividade. A subjetivação desses objetos depende de um contato íntimo com as pessoas, o que ativa sua subjetividade latente. Um objeto pode ser, portanto, "objeto subjetivo" (agente) ou "objeto subjetivado" (Santos-Granero 2013: 9). Os primeiros são os mais poderosos, que podem também ser perigosos, como é o caso das flautas kawoká dos Wauja apresentadas pelo autor. Esse grande poder/perigo exige formas adequadas de entrar em relação com esses objetos. Já os subjetivados são menos poderosos/perigosos e, com eles, pode-se estabelecer relações sem tantos cuidados. Essa proposta de Santos-Granero permite superar a dicotomia entre objetos rituais e objetos cotidianos e passar a pensá-los numa gradação de objetos mais e menos poderosos/perigosos. Se as máscaras ijáso são objetos subjetivos e poderosos/perigosos, as panelas e as ritxo(k)o podem ser entendidas como objetos subjetivados, ${ }^{7}$ menos poderosos/perigosos. ${ }^{8}$

A ritxo $(k) o$ participa de situações cotidianas. Cercadas por seus parentes e em ambiente doméstico, as mulheres modelam o barro, põem as peças para secar ao sol e as pintam depois de queimadas. Mesmo a queima das peças é feita no pátio da casa ou numa área próxima, e muitas vezes feita em conjunto com outras parentas (Campos 2007; Whan 2010; Lima e Silva 2011). Algumas das peças são dadas às meninas pequenas, mas a maioria é destinada à venda. Para vender, as ceramistas acionam mais uma vez suas parentas. Se uma

7 Mais à frente, sugerirei que a ritxo(k)o faz a mediação com uma outra categoria de alteridade: os brancos.

8 É importante ressaltar que, enquanto objetos que fazem representação de figuras humanas, as ritxo(k)o não estariam imediatamente livres desse perigo/poder. Em outros grupos sul-ameríndios, a representação está ligada a ideia de feitiço. Nenhuma relação entre ritxo( $k$ )o e feitiço é relatada na bibliografia ou me foi contada durante minha pesquisa de campo. Para uma análise do feitiço no contexto dos Aweti ver Vanzolini (2015) 
mulher vai à cidade, ou vai fazer uma viagem mais longa, não leva apenas suas peças de cerâmica para vender, leva também alguma parte da produção de sua mãe, irmãs e filhas. A ritxo(k)o está inserida nessa rede de parentes.

\section{FAZER CORPOS-PARENTES: A PRODUÇÃO DA PESSOA AMERÍNDIA}

A etnologia americanista esteve, desde a sua origem, empenhada em recusar modelos antropológicos que não se adequavam às novas realidades pesquisadas (Overing 1977; Seeger, Matta e Viveiros de Castro 1979). No que concerne o parentesco, as propostas americanistas recolocaram o problema clássico da consanguinidade e da afinidade. O fizeram ao negar o fundo biológico do parentesco e mostrar que no parentesco ameríndio as relações são estabelecidas através do corpo, e os grupos de pessoas estão em relação através de substâncias como sangue, sêmen, comida, etc. (Vilaça 2002). O parentesco não está dado de antemão, mas ele precisa ser produzido através da consubstancialidade. A criança que nasce precisa ser feita parente através da produção do seu corpo (Viveiros de Castro 2009).

Partilhar da substância dos parentes é uma condição que deve ser constantemente construída, através de atos de partilha de comida, carinho e cuidado (McCallum 1998; Rival 1998). Outro aspecto que se mostrou essencial foi o lugar da alteridade nesse processo (Vilaça 2002; Viveiros de Castro 2009). Os trabalhos de Carneiro da Cunha (1978) e Viveiros de Castro (1986) já haviam mostrado a importância da alteridade na produção da pessoa ameríndia. Mais recentemente, passou-se a evidenciar seu papel nos processos de aparentamento.

A alteridade é o ponto inicial do processo de parentesco ameríndio. Entre os Hauorani, o recém-nascido é um convidado que chega à casa dos anfitriões, seus pais, e deve ser transformado em parente gradualmente (Rival 1998). Entre os Piro, é apenas após o nascimento que se pode decidir se o recém-nascido é humano, podendo só então passar a ser aparentado, através do corte do cordão umbilical (Gow 1997). Vilaça (2002) defende este argumento ao analisar as restrições alimentares associadas ao nascimento (couvade). Para a autora, os corpos humanos são produzidos através de processos que os contrapõem a corpos animais. Estamos falando, portanto, de um corpo que se faz como corpo de parente, a partir de processos de consubstanciação gerados pela proximidade, intimidade, comensalidade, cuidado e carinho mútuos, e do desejo de se tornarem parentes (Vilaça 2002: 352). Como sugere Coelho de Souza (2001), em análise do parentesco xokleng, é preciso que os corpos se aparentem a partir da ativação e transformação de certas relações.

Na concepção karajá, o feto é formado através do acúmulo do sêmen no corpo da mulher (Donahue 1982). O homem contribui com sua substância, e a mulher é responsável pela sua transformação (Rodrigues 2008). Segundo Nunes (2012), o processo de parentesco tem início desde a concepção - e só 
pode ser encerrado com a morte. Uma mulher grávida deve praticar ou evitar certas ações, como passar sobre o rastro de cobras, que podem intervir na criança ainda em transformação dentro do seu corpo (Nunes 2012). Durante o parto, algumas parentas devem prestar auxílio à parturiente, sendo devidamente compensadas por essa ajuda. Segundo Donahue (1982), é comum que uma das avós do recém-nascido, provavelmente da linha materna (MM), seja aquela encarregada de segurar a criança e dar-lhe seu primeiro banho. A avó seguirá tendo um papel importante na criação de seu neto, podendo até mesmo amamentá-lo se necessário (Donahue 1982). Depois de seu primeiro banho, o bebê é completamente pintado com urucu. Apesar do processo de parentesco já ter se iniciado, a criança recém-nascida é como um outro, como um estranho (Rodrigues 1993). Segundo Nunes (2012), pode até mesmo ser identificada a categoria de aõni, que é a forma da alteridade por excelência. Por isso, nesse momento é essencial dar continuidade ao processo de aparentamento através da couvade (Nunes 2012).

O período que segue ao nascimento da criança é de cuidados intensos. As crianças dormem com seus pais ou avós e são tratadas com muito carinho e paciência e dificilmente não estão em contato físico com algum parente (Donahue 1982). Momentos importantes que marcam a progressiva autonomia da criança são o momento em que ela passa a andar e, posteriormente, o desmame. Gow (1997) também ressalta a importância do desmame para os Piro, também marca o início da sua alimentação com "comida legítima", o que permite que ela volte sua atenção para seus alimentadores, os seus parentes prospectivos [kinspeople-to-be]. O desmame, portanto, marca o início da oferta de alimentos e da comensalidade.

Nunes (2012) descreve as redes de parentesco articuladas não só pela troca de alimentos, comumente descrita na etnologia americanista, mas também pela troca de afetos e palavras. Nessa chave um outro aspecto do parentesco fica evidente, a memória.

\section{FAZER E DESFAZER PARENTES: LEMBRAR DO CARINHO, ESQUECER AS OFENSAS}

A memória aparece como essencial no processo de parentesco karajá. "Sem a memória do parentesco não se produz, não se alimenta os filhos, não se cuida deles, pois é ela que propicia os fluxos de alimentos, palavras, afetos, diversas substâncias, enfim, toda a gama de elementos cuja circulação assemelha os corpos dos parentes." (Nunes 2012: 146). É preciso lembrar dos parentes para dar movimento ao processo de aparentamento.

A criança que acaba de nascer passa a participar de um grupo doméstico. Os Karajá apresentam tendência à uxorilocalidade (Donahue 1982; Lima Filho 1991, 1994; Pétesch 1992; Toral 1992). Após o casamento, os novos casais 
preferem, mesmo que construam casas separadas, ficar próximos da casa da mãe da esposa, sendo comum os homens se mudarem para casa de suas sogras. O casamento marca o início das responsabilidades domésticas do rapaz e da moça, mas, mesmo que se engajem em atividades produtivas, não é esperado que os mais jovens contribuam com o "sustento" dos parentes (Nunes 2012). Assim, o casal sênior, que quase invariavelmente são aqueles que são avô e avó, tem um papel central na família, estando sempre implicados na criação tanto de seus filhos quanto de seus netos. Economicamente, mas também afetivamente (Nunes 2012). Grande parte da vida diária gira em torno das crianças, principalmente da necessidade de lhes "dar sustento" (Nunes 2012). As crianças são o centro dos momentos de socialidade, e é em torno delas que gira a vida cotidiana: vesti-las, banhá-las, pentear seus cabelos, observá-las, fazer-lhes carinho, alimentá-las. Os cuidados com as crianças são infinitos.

$\mathrm{O}$ ato de comer com os parentes, partilhando a mesma comida, é fundamental. Segundo Fausto (2002), comer, dar de comer, comer com e como alguém são todos processos de produção de corpos semelhantes, corpos-parentes. Segundo Nunes (2012), é importante para os Karajá que além da comida industrializada, "de branco", eles também possam oferecer a suas crianças e outros parentes a "comida inỹ": abóbora, mandioca, melancia, farinha de mandioca, carne de caça, peixes de escama, e, principalmente, a tartaruga (e seus ovos), o alimento iñ por excelência. "A alimentação é, certamente, um dos meios privilegiados de produção de corpos-parentes." (Nunes 2012: 141). Elas produzem um par: aquele que alimenta e aquele que é alimentado.

Todas essas atividades essenciais à vida e que buscam "dar sustento" ao cônjuge, filhos e netos só são realizadas pela memória que se tem destes (Nunes 2012). É pensado nos parentes que um homem sai para pescar ou trabalhar, que uma mulher cozinha e arruma a casa, faz artesanato para vender ou mesmo sai para trabalhar. Um solteiro não precisa trabalhar, não tem esposa e filhos dos quais se lembrar. Para Nunes (2012), a memória é a condição para o processo de parentesco. E é através de atos que evidenciam a memória do parentesco que o resultado do processo de aparentamento se dá a conhecer. É por meio da recíproca da memória que se sabe que o processo foi bem-sucedido, como quando uma criança tem reações positivas quando sua mãe lhe alimenta e aprecia a comida iñy (Nunes 2012).

Outro aspecto que é invocado nessa memória do parentesco são os brotyrè. Essa é uma posição que parentes da criança podem assumir em situações de liminaridade, tornando-se seus aliados no nascimento, nas iniciações e no casamento (Toral 1992). Pode haver tantos brotyrè quanto parentes se oferecerem, sendo mais comum que as mulheres assumam essas posições (Rodrigues 2008). Aqueles que se apresentam para ser brotyrè nessas diversas situações recebem presentes valiosos dos pais da criança, principalmente na iniciação masculina (Toral 1992). Ao realizarem esses pagamentos, as famílias acabam 
por perder quase todos os bens que possuem (Rodrigues 1993). Segundo Rodrigues (2008), apesar do ônus econômico, o grande número de parentes que se apresentam para ser brotyrè representa maior prestígio para a criança e para seus pais, que conseguem pagar por essa honra. Esta se originaria tanto na generosidade (wowi), característica altamente valorizada, quanto na demonstração de que se tem muitos parentes (Rodrigues 2008).

Ser brotyrè pode ser uma grande demonstração de carinho, principalmente quando se abre mão do pagamento. Quando, depois da narrativa empolgada da iniciação de seu neto, em que foi enfatizada a beleza dos enfeites e objetos produzidos para a ocasião, perguntei a Dorewaru o que ela havia pedido para ser brotyrè, ela me disse: "não pedi nada não". Essa narrativa surpreendeu-me, em oposição às incríveis histórias de grandes e valiosos presentes que me haviam contado até então. Com o tempo, outros relatos como este surgiram. Algumas mulheres quando foram brotyrè de crianças muito próximas ou pelas quais tinham grande afeição não pediam retribuições. Numa manhã, cheguei à casa de Myixa e ela tinha pintado a batata da perna e colocado às peninhas brancas das meninas pubertárias, uma sobrinha que morava na aldeia de Fontoura teve sua primeira menstruação e Myixa ofereceu-se como brotyrè. Eu prontamente perguntei o que ela tinha requisitado como pagamento e ela me respondeu: "eu faço porque gosto". Narubia, que me acompanhava nessa visita, completou: "ela faz porque gosta da sobrinha, não pede nada não". Se voluntariar como brotyrè de uma criança é mais uma maneira de produzir memória de carinhos e cuidados. "Todas as pessoas se lembram com carinho os seus brotyrè do tempo em que se tornaram moças e rapazes. São geralmente avôs e avós, com predominância dessas últimas, e dos irmãos mais novos e mais velhos dos pais, com predominância das irmãs do pai e da mãe." (Toral 1992: 135).

Mas, se os parentes da criança têm papel fundamental no seu processo de aparentamento, não se pode deixar de notar que o processo de parentesco é sempre uma via de mão dupla. Um processo não reciprocado é um processo falho que não produziu corpos-parentes. "Para tornar-se parente, é preciso lembrar e ser lembrado." (Nunes 2012: 142). Por isso, há muita preocupação no caso de crianças que não apreciam a comida inỹ (Nunes 2012) e que não aprendem a andar (Donahue 1982). Esses comportamentos são vistos como quebras no processo de aparentamento, e indícios de que o corpo da criança pode estar se produzindo como não-parente. É importante ressaltar o papel ativo da criança nesse processo. Não basta que os adultos se empenhem para realizar o processo, ele depende também do esforço ativo da criança. Patrícia Rodrigues também enfatiza que o parentesco entre os Javaé é um processo:

"Os Javaé dizem que só aqueles que foram criados juntos e que se visitam com regularidade, que comem uns na casa dos outros, que conversam alegremente e que brincam entre si, que dão conselhos uns aos outros, que 
se oferecem para ser bòròtyrè das crianças da família, que levam os sobrinhos reais ou classificatórios para as brincadeiras rituais (no caso dos tios), que se ajudam mutuamente nos duelos verbais e corporais com os inimigos, que choram ritualmente uns pelos outros, entre outras manifestações de afetividade e reciprocidade, é que são 'considerados parentes' " (Rodrigues 2008: 623)

Outro ponto importante do processo de parentesco é que ele pode ser revertido. Da mesma forma que ele pode falhar, ele também pode ser desfeito, transformando parentes em não-parentes. Nunes (2012) descreve alguns casos em que as dinâmicas de oposição políticas levam a um esquecimento, um apagamento das relações de parentesco. Lembrar-se dos parentes produz os laços de parentesco, mas lembrar das ofensas feitas por parentes leva a desfazer esses mesmos laços. Para que o processo do parentesco seja bem-sucedido, "é necessário lembrar da comida recebida/dada, das demonstrações de afeto e respeito, etc., mas é igualmente necessário esquecer as ofensas, os comportamentos excessivos ou desrespeitosos que eventualmente emergem" (Nunes 2012: 159). O processo contrário leva a um processo de desaparentamento.

Lembrar persistentemente dos desentendimentos que se tem com um parente é lembrar dele ou dela como um não-parente, como um diferente. Essa memória "indevida" pode provocar uma fratura entre parentelas, produzindo-as como diferentes, e isso, por sua vez, pode provocar a divisão da aldeia (Nunes 2012). Os conflitos políticos em uma aldeia fazem eclodir uma espécie de memória latente das ofensas: quando algum evento catalisa a fissura entre parentelas, questões muito antigas - desentendimentos, ofensas e agressões entre os pais ou avós dos envolvidos - são trazidas à tona e aparecem como evidência do comportamento inapropriado do grupo contrário (Nunes 2012).

A memória dos afetos, carinhos e cuidados efetiva o processo de produção dos corpos-parentes, enquanto a memória das desavenças e desentendimentos esvaece-o. A produção de corpos-parentes é um processo sempre em risco de falhar, ou pela não reciprocidade ou pela quebra.

\section{PRESENTEAR COM RITXO $(K) O$}

Entre os ameríndios, o parentesco é um processo permeado pelo perigo de não se conseguir efetivá-lo. São os atos de cada pessoa que estabelecerão essas relações e produzirão ou não corpos aparentados. É a partir da percepção dessa fluidez que proponho repensar um dos usos bem documentados da ritxo(k)o pela bibliografia, o ato de a avó presentear a neta com ritxo(k)o (Costa 1968; Simões 1992; Campos 2007; Whan 2010).

Durante o tempo que passei em Santa Isabel, fui gentilmente acolhida na casa de Komytira. Ela é casada e teve com seu marido oito filhos. Komytira é 
uma ceramista reconhecida na aldeia de Santa Isabel do Morro e produz muita cerâmica para venda. Ela possui quatro netas com idades entre um e cinco anos. Suas duas netas mais velhas são Kosianaru (SD), que tem cinco anos, e Mutiwala (DD), que tem dois anos.

Mutiwala e sua mãe vivem na mesma casa que Komytira, enquanto Kosianaru mora com sua mãe e avó materna (MM) em outra aldeia, e apenas visita a avó paterna (FM) por certos períodos. Há uma disputa sobre o local de moradia do pai de Kosianaru, que deveria morar com sua esposa, próximo a casa de sua sogra. Contudo, Komytira insiste que ele não siga a tendência uxorilocal e permaneça em sua casa. A disputa pela residência do casal tornou-se um ponto de tensão entre essas duas famílias.

A bibliografia descreve uma forte tendência à uxorilocalidade entre os grupos karajá (Lima Filho 1994; Pétesch 1992; Toral 1992; Rodrigues 2008); isso significa que, em geral,

Figura 1

Diagrama da genealogia resumida de Komytira

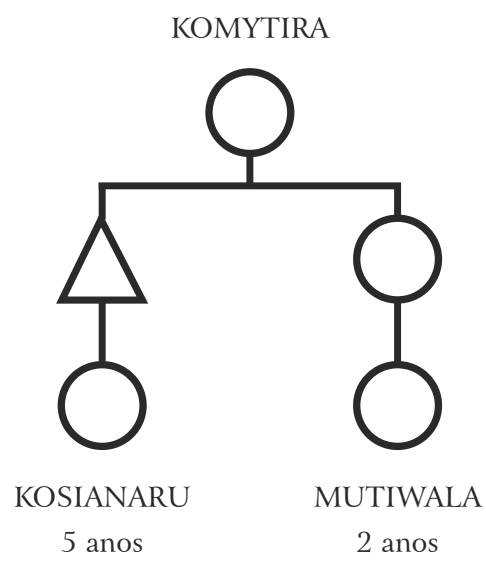

Fonte: elaboração própria.

as mulheres permanecem na casa de seus pais e nas suas aldeias de origem, enquanto os homens tendem a se dispersar (Toral 1992). As mulheres geralmente passam a vida inteira nas suas casas, enquanto os homens têm de se mudar para a casa de sua sogra após o casamento (Nunes 2012). Atualmente, muitos dos novos casais preferem construir novas residências (neonatalidade), mas os locais procurados para o estabelecimento das novas residências permanecem próximos à casa da mãe da esposa (Toral 1992; Lima Filho 1991). Ao casar-se, o genro passa a ter de trabalhar com o sogro e sua família (Toral 1992). Segundo Schiel, “o início de um casamento é dominado por uma tensão constante, sobretudo entre o sogro e seu novo genro, havendo entre eles uma disputa velada" (2005: 88). A questão da moradia pós-marital é um grande dilema para os jovens rapazes, que têm de deixar de viver "entre os seus" e ir viver "entre outros" na casa de sua esposa. Se o casamento exigir que o noivo se mude para outra aldeia, esse dilema pode agravar-se, como é o caso que aqui apresentado.

Mutiwala (DD), apesar de ter apenas dois anos, e ser considerada "muito nova" pela avó e pela mãe para ter ritxo(k)o, já foi presenteada com um conjunto, do qual só sobrou uma peça. A idade ideal para presentear as meninas está relacionada com sua capacidade de manter e conservar as peças (Campos 
2007), meninas muito novas acabam quebrando rapidamente a maioria do conjunto. Por outro lado, Kosianaru (SD), que tem idade considerada adequada para ser presenteada, nunca recebeu um conjunto de Komytira. Quando incentivada por uma de suas filhas a presentear Kosianaru, Komytira desconversa. A presteza com que Komytira presenteou Mutiwala, mesmo em momento inapropriado, parece enfatizar os fortes laços estabelecidos com sua filha. Já a recusa em presentear Kosianaru aparece como escolha ativa de não reforçar essa relação. $\mathrm{O}$ ato de presentear suas netas com ritxo(k)o aparece como uma forma de ativar as relações com a filha e a neta, e não presentear como uma maneira de opor-se ao casamento do filho, e manter um afastamento com relação à sua nora.

Nesse ponto é preciso voltar a bibliografia sobre a ritxo(k)o para marcar uma diferença importante e significativa de abordagem. Desde 1891, existem indícios na bibliografia de que as bonecas karajá são brinquedos das meninas (Ehrenreich 1948 [1891]). Muitos outros registros foram feitos pelos pesquisadores das ritxo $(k)$ o sendo usadas pelas meninas karajá como brinquedo (Campos 2007; Chiara 1970; Costa 1968; Lima e Silva 201 1; Simões 1992; Whan 2010). Mas é Campos (2007) que primeiramente reflete sobre o ato de dar a ritxo(k)o a alguém. Segundo a autora,

"As meninas recebem uma 'família' de bonecas, composta por peças que representam os pais, os irmãos, os avós. Em outras palavras, as avós presenteiam, espelham nas hykynaritxoko sua ancestralidade, seguindo padrões tradicionais da constituição familiar. As bonecas, além de simularem as diversas fases do crescimento biológico e de suas respectivas categorias sociais, bem como a forma antiga da estrutura familiar karajá, reproduzem o ato tradicional das avós presentearem as netas, que é mantido e reafirmado nas relações sociais, submetido a regras para esse acontecimento." (Campos 2007: 47)

A autora caracteriza o presentear como um "ato tradicional". Mas ele é muito mais do que isso. Ele faz parte de um conjunto de ações que constroem avós e netas como corpos aparentados. A própria relação com as crianças merece um novo olhar. Presentear uma criança não é algo que se faz porque se é avó, essa é uma entre várias ações que têm como objetivo construir a relação de avó e neta. Sugiro, portanto, que a causalidade é inversa ao que propôs Campos (2007). Não é porque se é avó que se busca presentear as netas, mas é através do ato de presentear que a mulher se faz avó e faz, ao mesmo tempo, a neta. O par avó-neta constrói-se não só sobre essa ação, mas também mutuamente através de diversas relações de carinho e cuidado. É ao alimentar seus netos, dar-lhes banho todas as tardes, dar-lhes presentes sempre que pode, proteger-lhes assumindo a posição de brotyrè, dar-lhes conselhos por toda a vida, que uma mulher se produz como lahi (avó); e é ao procurar ser alimentada, 
retribuir aos afetos, chamar pelos termos corretos de parentesco e se lembrar de sua lahi que uma menina se constrói enquanto dee (neta). É essa necessidade de reciprocidade de que falou Nunes (2012). Um processo bem-sucedido na produção de corpos-parentes depende da dupla ação: lembrar e ser lembrado.

\section{VENDER RITXO(K)O: A RELAÇÃO COM OS TORI}

Uma parte das peças produzidas pelas ceramistas é dada às meninas pequenas. Mas a grande maioria é destinada ao comércio. A venda das ritxo(k)o para os tori é importante fonte de renda para muitas famílias karajá. Ao perceber a venda das peças como parte de uma rede de relações, é importante refletir sobre as relações que os grupos estabelecem com os brancos.

O contato entre os Karajá e os brancos é antigo, havendo registros que datam do século XVI (Lima e Silva 2011). O comércio de peças cerâmicas, inclusive de $\operatorname{ritx}(k) o$, é registrado pela literatura desde Ehrenreich (1948 [1891]). Nesse período, houve diversas tentativas de "pacificação" de grupos de regióes cobiçadas, como a do rio Araguaia, culminando em aldeamentos de diversos grupos (Karasch 1992). O início do século XIX foi marcado pela retomada de suas terras e pela crescente hostilidade para com os brancos (Pétesch 1992). Os conflitos entre os Karajá e colonos persistiram através do século XIX (Portela 2006).

A chegada do século XX é marcada pela criação do SPI (Serviço de Proteção ao Índio) (Pétesch 1992). O órgão tinha como objetivo proteger os povos indígenas ao mesmo tempo que garantia sua integração harmoniosa à sociedade nacional (Prestes Filho 2006). No Araguaia, implementaram a criação de gado e a cultura de arroz (Lima e Silva 2011). Nesse período a colonização agropastoril havia expandido grandemente, com muitas famílias de colonos se instalando na margem mato-grossense do rio: área de antigas aldeias karajá tornaram-se as atuais cidades de São Félix do Araguaia, Luciara e Santa Terezinha (Pétesch 1992). Whan (2010) ressalta que as ritxo(k)o se tornaram os primeiros presentes ou "agrados" dos Karajá para os regionais.

Entre as décadas de 1940 e 1960, uma nova preocupação com a questão indígena surgiu por parte dos presidentes Getúlio Vargas e, posteriormente, Juscelino Kubitschek, que deram grande valor à ocupação e desenvolvimento do Centro-Oeste brasileiro. Segundo Pétesch (1992), os Karajá foram os primeiros indígenas a serem utilizados como "vitrine" das políticas do governo nacional. Nesse período, diversos elementos de infraestrutura foram construídos na aldeia de Santa Isabel do Morro, como hospital e escola, além de um hotel de luxo (Pétesch 1992). As ritxo(k)o foram parte importante desse período, aparecendo como emblema da cultura karajá. Tornaram-se muito populares entre os turistas que visitavam a região do Araguaia, e logo passaram a ser vendidas em São Paulo e no Rio de Janeiro (Chiara 1970). 
Os estudos sobre as ritxo(k)o, realizados desde então, discorrem longamente sobre uma mudança de estilo que haveria ocorrido no período. Para Simões (1992), uma mudança importante alterou as ritxo(k)o consideravelmente: elas passaram de brinquedo de criança para artigo de comércio. Segundo ele foi devido a essa mudança que as peças começaram a ser queimadas e a ser mais representativas, o que marcaria a diferença entre bonecas antigas e bonecas modernas.

Faria (1959), por outro lado, nomeia essa distinção como diferenças de fases. A primeira, a fase antiga, é representada pelas peças coletadas antes de 1950. Essas eram produzidas em barro não cozido e o cabelo era feito de cera de abelha. Nelas sempre são representadas as marcas tribais (tatuagem nas maçãs do rosto) e o umbigo e a marcação do sexo é feita pela tanga de líber para as mulheres e por órgãos sexuais realistas e pelo tembetá para os homens. $\mathrm{Na}$ fase moderna, as peças passaram a ser cozidas e o cabelo passou a ser representado por barro. A maior resistência provinda do cozimento iniciou uma fase de grande experimentação e de "dinamismo criador". Surgem as composições cênicas, que permitem realizar até mesmo "extravagantes ensaios escultóricos”. Os Karajá buscariam uma nova linguagem plástica que pudesse ser compreendida não só no mundo karajá, mas nesse novo universo de padrões estéticos tori.

Chiara (1970) também relaciona a mudança da forma das bonecas à influência estrangeira e ao comércio. A antropóloga nota que a venda nas cidades impulsionou o gênero "bibelô", as peças feitas sobre suportes para serem exibidas em prateleiras. Esse tipo de comércio também incentivou a constante renovação dos temas retratados na cerâmica, o que a autora chama de "modas". No entanto, além do comprador interessado em estatuetas decorativas, havia outro tipo de comprador: os colecionadores. Enviados principalmente por museus, eles sabiam que a cerâmica oferecida aos turistas não era como "as primeiras bonecas", como as ritxo(k)o "originais". Os colecionadores procuravam objetos etnológicos "autênticos". Sem encontrá-los no mercado karajá eles os encomendavam. A autora sugere que os Karajá percebiam diferenças nos compradores e, assim, produziam diferentes peças para cativar esses diferentes tori: o estilo tradicional e o estilo moderno.

Apesar de o presente artigo não ter a intenção de discutir o tema da transformação da cultura, é importante fazer uma nota sobre como as reflexões dos autores acima citados estão marcadas pela teoria antropológica de sua época, e como ela se distancia das nossas concepções atuais. A ideia de práticas tradicionais e práticas modernas vem de uma visão estática da ideia de cultura, uma abordagem de traços culturais, própria da antropologia dos anos 1950, mas da qual hoje podemos nos afastar. Nessa concepção não mais há coisas autênticas em oposição a coisas transformadas, que são como que impurezas dentro do sistema cultural. Sob esse paradigma da aculturação, os povos indígenas são 
vítimas da história, danificados pela penetração dos povos europeus e sociedades nacionais. Mas "a tradição não é um corpus fechado que persiste no tempo" (Cohn 2001: 38). A transformação faz parte da cultura, é sua própria forma de existir no tempo.

As relações entre os tori e os Karajá são bastante antigas. A venda de ritxo(k)o tem um papel importante na construção dessas relações. Whan (2010) observa o estabelecimento de relações de dois tipos com os brancos: relações de amizade e relações comerciais. Se, no primeiro caso, procura-se formar alianças para além do grupo familiar, amizades, principalmente com moradores das cidades próximas; no segundo caso, as ceramistas buscam angariar dinheiro.

Gostaria de sugerir, apoiada nas reflexões de Chiara (1970), que existe um terceiro tipo de relação que as ceramistas buscam produzir com os tori: ela envolve os pesquisadores interessados na cerâmica karajá como objeto de estudo. Essas relações não estão focadas apenas no dinheiro, que também pode circular nessas situações; mas em outros ganhos que se pode obter na relação com pesquisadores. A patrimonialização das ritxo(k)o é o exemplo emblemático dos benefícios desse tipo de relação. Se num primeiro momento a venda das ritxo(k)o e de outros objetos produzidos como artesanato são modos de estabelecer relações com os tori, também defendo que a venda pode ser entendida como mais uma maneira de produzir as relações de parentesco. Apresentarei esse argumento a seguir.

\section{VENDER CERÂMICA PARA ALIMENTAR E PRESENTEAR OS PARENTES}

Para defender que a venda das ritxo $(k) o$ também integra o processo de produção de corpos-parentes, preciso primeiro esclarecer como a alteridade é parte desse processo. Para tanto, é preciso pensar sobre a transmissão de ijasò. São os próprios ijasò que informam o xamã (hàri) que devem começar os preparativos para a festa (Lima Filho 1991; Pétesch 1992; Toral 1992). O xamã, então, dirige-se a algum adulto da aldeia e conta que trouxe um ijasò para seu filho, filha, sobrinho, sobrinha, neto ou neta (Donahue 1982). O ijasò passa, desse modo, a "pertencer" à criança, e seu pai e sua mãe tornam-se pai e mãe de ijasò e devem passar a alimentá-lo durante sua estadia na casa dos ijasò (Toral 1992). Toda a parentela é mobilizada para produzir os alimentos que serão consumidos no ritual (Pétesch 1992). É a comida que põe em operação as tykydisi (jogos rituais), ela deve ser oferecida antes, durante e depois de cada performance dos ijasò, que aparecem como uma dupla de máscaras (Lourenço 2008).

Transmitir o ijasò para uma criança é uma forma adequada de entrar em contato com essa alteridade. Essa relação gera benefícios que permitem que a criança seja aparentada de forma boa e correta. Donahue (1982) ressalta que um dos principais motivos das pessoas desejarem ser pai ou mãe de ijasò é para 
que suas crianças os vejam, o que lhes é muito favorável. "A associação com os ijasò é vista como benéfica, garante a saúde e propicia o desenvolvimento da pessoa" (Toral 1992: 161). Segundo Pétesch (1992), a criança que "possui" um ijasò é uma criança amada e a ela é assegurada ajuda e proteção.

Mas há mais. Se a transmissão dos ijasò para a criança é importante para que ela cresça forte e não fique doente, esse também é um dos modos adequados e seguros de entrar em contato com os ijasò: "O contato com os ijasò é considerado perigoso se não for conduzido de maneira adequada. Quando é feito por mulheres pode causar problemas e mortes" (Toral 1992: 158). As festas de ijasò seriam um modo de amenizar esse perigo através de um processo de filiação, no qual o ijasò torna-se um "bien-enfant" (propriedade-criança) de seus pais adotivos (Pétesch 1992). Fazer do ijasò um filho, ou um nohõ, é uma forma de aproximar-se dessa categoria de alteridade de forma apropriada, amenizando os perigos dessa relação.

Sugiro que o mesmo possa ser dito do comércio de ritxo(k)o. Esta é uma forma adequada de entrar em contato com a alteridade dos tori e deles conseguir benefícios, como o dinheiro. Este é, então, usado para a compra de comida e presentes que são essenciais para a produção dos corpos-parentes. A venda das ritxo(k)o é um dos modos possíveis de dar sustento aos parentes. Se, como sistematizou Viveiros de Castro (2009), para as terras baixas é preciso alteridade para produzir as crianças e os parentes, no caso karajá, as crianças são um dos meios adequados para estabelecer relações com a alteridade ijasò e, assim, conseguir benefícios, como a produção de corpos-parentes. Defendo que a venda de ritxo( $k$ )o também pode ser entendida como uma forma de apropriar-se da alteridade, mas, agora, da alteridade dos tori.

Outras pesquisas mostraram lugar importante dos objetos nas relações com a alteridade de estrangeiros. Barbosa (2007) observa entre os Apparai e Wayana que os objetos, através das trocas, possuem um lugar importante na sua relação com não parentes e visitantes, como uma forma de "amansar" diversas categorias de outros. "[...] A troca aparece como forma de incorporação do Outro e também de agenciamento e manutenção das diferenças.” (Barbosa, 2007). Também César Gordon (2003) fala do lugar do dinheiro na produção das relações de parentesco. Há três formas dos Xikrin pensarem o dinheiro. Primeiro, como um simples instrumento interpessoal de troca; segundo, como um signo de predação do estrangeiro, a incorporação de uma parte bonita ou poderosa; e, em terceiro lugar, como um objeto que convém à relação entre parentes. No início de sua pesquisa, o antropólogo pensava que o dinheiro mediava apenas as relações da aldeia com o exterior, sendo que muitas das falas dos Xikrin diziam ser imoral pagar dentro da aldeia com dinheiro. Mas, com o tempo, ele percebeu que na aldeia não se pagava por serviços com dinheiro, entretanto, ele poderia ser dado ou emprestado para os parentes. Nesses casos, o dinheiro assumia o caráter de presente, de troca generosa. Quando as pessoas da aldeia 
reclamavam que os chefes não as "pagavam" com dinheiro, estavam dizendo que os chefes não as tratavam e não as reconheciam como seus próprios parentes - a quem se "paga" e presenteia com dinheiro em demonstração de cuidado. Por isso, "[...] as transações em dinheiro no interior da comunidade - i.e., o 'pagamento' no sentido Xikrin - podem, precisamente, marcar o reconhecimento de parentesco." (Gordon 2003: 17). Mesmo as mercadorias, os produtos industrializados, são usadas entre os Xikrin para alimentar, presentear e agradar os parentes (Gordon 2003). Presentear os parentes é uma forma de lembrá-los (Gordon 2003).

Assim como os cuidados cotidianos, a oferta de comida iny, o uso dos termos corretos de parentesco e os brotyrè tornam-se memórias do parentesco que permitem a produção de corpos aparentados, a oferta de comida industrializada e oferta de presentes comprados na cidade também compõem essas memórias. Angariar dinheiro e bens industrializados tem dois aspectos: é uma forma de se relacionar com os tori, mas também é uma das formas de produzir parentes. A ritxo(k)o é um objeto que consegue ativar relações nessas duas redes. Se através dela é possível se relacionar com os brancos de maneira adequada, criando laços de aliança, também é através dela que se consegue dinheiro e bens industrializados que são transformados em comida e presentes, maneiras de demonstrar carinho e cuidado com os parentes, lembrar deles e em contrapartida produzir memórias desse carinho e cuidado.

\section{CONSIDERAÇÕES FINAIS}

A ritxo(k)o faz parte das redes de relações que são, em primeiro lugar, as de parentesco. Envolvidas nessa intensa rede, a produção dessa cerâmica ativa relações entre grupos de mulheres aparentadas, que se unem no pátio entre suas casas para modelarem e pintarem as peças juntas. Essas mesmas mulheres também se ajudam na hora de realizar o comércio de suas peças. Algumas das ritxo(k)o são feitas para as meninas pequenas da família. $\mathrm{O}$ ato de presenteá-las é muito mais do que um "ato tradicional" (Campos 2007). Ele faz parte de um conjunto de ações que constroem avós e netas como corpos aparentados. A alimentação, os cuidados diários, o uso dos termos corretos de parentesco e presentes, como as ritxo(k)o, mas também de bens industrializados, a troca de afetos, o aconselhamento, a proteção através da categoria de brotyré são parte das ações que garantem um processo bem-sucedido de parentesco. A ritxo(k)o, portanto, é constituída através dessas relações ao mesmo tempo que as constitui. Ela faz parte dessas redes em que adultos e crianças participam ativamente no processo de produção de seus corpos-parentes.

No entanto, a rede de relações da ritxo $(k) o$ estende-se para além do parentesco, através do comércio, ela também propicia relações com os tori. Essas relações podem ser de aliança e amizade, comerciais ou com pesquisadores. 
O primeiro caso ocorre através da troca de presentes com vizinhos das aldeias. As relações com os pesquisadores também têm grande importância e geram oportunidades para os Karajá, como a organização de exposições em grandes museus do país e a patrimonialização da ritxo(k)o, que conferiu grande visibilidade ao grupo, indo ao encontro de muitas de suas demandas políticas. Já as relações comerciais, num primeiro momento, visariam simplesmente obtenção de dinheiro. Sugiro que, após a obtenção do dinheiro, este é transformado em alimentos e presentes, que voltam a ativar a produção de corpos-parentes. Dessa forma, a relação com os tori via ritxo(k)o pode ser colocada em paralelo com as relações com os ijasò via sua transmissão: ambos são formas adequadas de entrar em contato com diferentes alteridades, e delas conseguir benefícios que permitem pôr em movimento o processo de aparentamento. Apesar de serem um objeto de pouco poder/perigo (Santos-Granero 2013), as ritxo(k)o mediam a relação com essa categoria de alteridade, os tori, permitindo que ela alimente a produção de corpos parentes.

\section{BIBLIOGRAFÍA}

BARbOSA, Gabriel Coutinho, 2007, Os Aparai e Wayana e Suas Redes de Intercâmbio. São Paulo: Universidade de São Paulo, dissertação de mestrado.

CAMPOS, Sandra, 2007, Bonecas Karajá: Modelando Inovações, Transmitindo Tradições. São Paulo: Pontifícia Universidade Católica.

CHIARA, Wilma, 1970, Les poupées des indiens Karajá. Nanterre: Université de Paris X, tese de doutorado.

COHN, Clarice, 2001, "Culturas em transformação: os índios e a civilização", São Paulo em Perspectiva, 15 (2): 36-42.

COSTA, Maria Heloisa Fénelon, 1968, A Arte e o Artista na Sociedade Karajá. Brasília: Fundação Nacional do Índio.

CUNHA, Maria Manuela Carneiro da, 1978, Os Mortos e os Outros: Uma Análise do Sistema

Funerário e da Noção de Pessoa entre os Índios Krahó. São Paulo: Hucitec.

DAVIES, Irvine, 1968, "Some macro-Jê relationships", International Journal of American Linguistics, 34 (1): 42-47.

DONAHUE, George, 1982, A Contribution to the Ethnography of the Karajá Indians of Central

Brazil. Charlottesville: Universidade da Virgínia, tese de doutorado.

EHRENREICH, Paul, 1948 [1891], "Contribuições para etnologia do Brasil", Revista do Museu Paulista, 2: 7-135.

FAUSTO, Carlos, 2002, "Banquete de gente: comensalidade e canibalismo na Amazônia", Mana, 8 (2): 7-44.

FARIA, Luiz de Castro, 1959, A Figura Humana na Arte dos Índios Karajá. Brasília: Funai. 
FARIAS, Joana, 2015, Modelando Parentes: Sobre as Redes de Relações da Ritxo(k)o entre os Karajá.

São Paulo: Universidade de São Paulo, dissertação de mestrado.

GELl, Alfred, 1998, Art and Agency: An Anthropological Theory. Oxford: Oxford University Press.

GORDOn, Cesar, 2003, Folhas Pálidas: a Incorporação Xikrin (Mebêngôkre) do Dinheiro e das Mercadorias. Rio de Janeiro: Universidade Federal do Rio de Janeiro, tese de doutorado. GOW, Peter, 1996, "Aesthetics is a cross-cultural category: against the motion", in T. Ingold (org.), Key Debates in Anthropology. Londres e Nova Iorque: Routledge.

GOW, Peter, 1997, "O parentesco como consciência humana: o caso dos piro", Mana, 3 (2): 39-65.

KARASCH, Mary, 1992, “Catequese e cativeiro: política indigenista em Goiás: 1780-1889”, in M. M. Carneiro da Cunha (org.), A História dos Índios no Brasil. São Paulo: Companhia das Letras, 397-412.

LIMA, Nei Clara de, e Telma Camargo da SILVA (orgs.), 201 1, Bonecas Karajá: Arte Memória e Identidade Indígena no Araguaia. Dossiê Descritivo dos Modos de Fazer Ritxoko. Goiânia: Universidade Federal de Goiás/Museu Antropológico.

LIMA FILHO, Manuel Ferreira, 1991, Os Filhos do Araguaia: Reflexões Etnográficas sobre o Hetohoky, Um Rito de Iniciação Masculina Karajá. Brasília: Universidade de Brasília, dissertação de mestrado.

LIMA FILHO, Manuel Ferreira, 1994, Hetohoky: Um Rito Karajá. Goiana: Editora da UCG.

LOURENÇO, Sônia Regina, 2008, "A dança dos Aruanã: mito, rito e música entre os Javaé”, Sociedade e Cultura, 11 (2): 213-223. Universidade Federal de Goiás, Brasil.

MCCALluM, Cecilia, 1998, "Alteridade e sociabilidade Kaxinauá", Revista Brasileira de Ciências Sociais, 13 (38): 127-136.

NETO, Aristóteles Barcelos, 2008, Apapaatai: Rituais de Máscaras no Alto Xingu. São Paulo: Editora da Universidade de São Paulo.

NUneS, Eduardo Soares, 2012, No Asfalto Não Se Pesca: Parentesco, Mistura e Transformação entre os Karajá de Buridina (Aruanã - GO). Brasília: Universidade de Brasília, dissertação de mestrado.

OVErIng, Joanna, 1977, Social Time and Space in Lowland South American Societies. Paris: Sociedade dos Americanistas, Museu do Homem, 205-215.

OVERING, Joanna, 1996, "Aesthetics is a cross-cultural category: against the motion", in T. Ingold (org.), Key Debates in Anthropology. Londres e Nova Iorque: Routledge.

PETESCH, Natalie, 1992, La pirogue de sable: Pérennité cosmique et mutation sociale chez les Karajá du Brésil Central. Nanterre: Université de Paris X, tese de doutorado.

PORTELA, Cristiane de Assis, 2006, Nem Ressurgidos, nem Emergentes: a Resistência Histórica dos Karajá de Buridina em Aruanã - GO (1980-2006). Goiânia: Universidade Federal de Goiás.

PRESTES FILHO, Ubirajara de Farias, 2006, O Indígena e a Mensagem do Segundo Advento: Missionários Adventistas e os Povos Indígenas na Primeira Metade do Século XX. São Paulo: Universidade de São Paulo, tese de doutorado.

RIBEIRO, Berta Gleizer, 1986, "Prólogo”, in Darcy Ribeiro (org.), Suma Etnológica Brasileira: Edição Atualizada do Handbook of South American Indians - vol. 2 - Arte Índia. Petrópolis: Vozes.

RIVAL, Laura, 1998, "Androgynous parents and guest children: the Huaorani couvade", The Journal of the Royal Anthropology Institute, 4 (4): 619-642. 
RODrigues, Patrícia Mendonça, 1993, O Povo do Meio: Tempo, Cosmo e Gênero entre os Javaé da Ilha do Bananal. Brasília: Universidade de Brasília.

RODRIGUeS, Patrícia Medonça, 2008, A Caminhada de Tanỹxiwè: Uma Teoria Javaé da História. Chicago: Universidade de Chicago.

SANTOS-GRANERO, Fernando, 2013, "Introduction: Amerindian constructional views of the world", in Fernando Santos-Granero (org.), 2009, The Occult Life of Things: Native Amazonian Theories of Materiality and Personhood. Tucson: The University of Arizona Press, $1-29$.

SCHIEL, Helena Moreira, 2005, O Vermelho, o Negro e o Branco: Modos de Classificação entre os Karaja do Brasil Central. São Paulo: Universidade de São Paulo, dissertação de mestrado.

SEEGER, Anthony, Roberto da MATTA, e Eduardo VIVEIROS DE CASTRO, 1979, "A construção da pessoa nas sociedades indígenas", Boletim do Museu Nacional, 32: 2-19.

SIMÕES, Manuel Ferreira, 1992, Cerâmica Karajá e Outras Notas Etnográficas. Goiânia: UCG/ IGPA.

SOUZA, Marcela Coelho de, 2001, "Nós os vivos: 'construção da pessoa' e 'construção do parentesco’ entre alguns grupos jê”, Revista Brasileira de Ciências Sociais, 16 (46): 69-96.

STRATHERN, Marilyn, 1996, "The concept of society is theoretically obsolete: for the motion”, in T. Ingold (org.), Key Debates in Anthropology. Londres e Nova Iorque: Routledge.

TORAL, André, 1992, Cosmologia e Sociedade Karajá. Rio de Janeiro: Universidade Federal do Rio de Janeiro.

VAnZOLINI, Marina, 2015, A Flecha do Ciúme: o Parentesco e Seu Avesso Segundo os Aweti do Alto Xingu. São Paulo: Terceiro Tempo.

VILAÇA, Aparecida, 2002, "Making kin out of others in Amazonia”, The Journal of the Royal Anthropology Institute, 8 (2): 347-365.

viveiros DE CASTro, Eduardo, 1986, Araweté: Os Deuses Canibais. Rio de Janeiro: Jorge Zahar Editor/Anpocs.

VIVEIROS DE CASTRO, Eduardo, 1999, "Etnologia brasileira”, in S. Miceli (org.), O que Ler na Ciência Social Brasileira (1970-1995) - Antropologia (Volume 1). São Paulo; Brasília: Editora Sumaré: ANPOCS; CAPES, 109-223

VIVEIros DE CASTRO, Eduardo, 2009, A Inconstância da Alma Selvagem. São Paulo: Cosac Naify.

WHAN, Chang, 2010, Ritxoko: a Voz Visual das Ceramistas Karajá. Rio de Janeiro: UFRJ/EBA/ PPGAV.

WÜST, Irmhild, 1975, “A cerâmica karajá de Aruanã”, Anuário de Divulgação Científica, 2 (2): 99-165.

Receção da versão original / Original version

Aceitação / Accepted

Pré-publicação online / Pre-published online
$2019 / 01 / 14$

$2020 / 07 / 17$

$2021 / 05 / 18$ 